\title{
VEM PRA RUA! POR \\ MAIS QUALIDADE NO TRANSPORTE PÚBLICO
}

\section{AVENIDAS DE TODO O BRASIL FORAM TOMADAS PELO GRITO: "VEM PRA RUA CONTRA O AUMENTO!" DEPOIS DE ANOS ADORMECIDA, A POPULAÇÃO SE MOBILIZOU E QUER MAIS QUALIDADE NO TRANSPORTE PÚBLICO. A CAUSA É JUSTA, MAS É PRECISO ENTENDER OS POSSÍVEIS CAMINHOS PARA CHEGAR LÁ}

\author{
| POR CIRO BIDERMAN
}

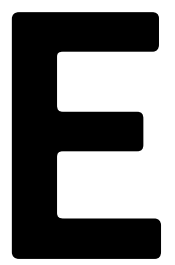

m junho deste ano, manifestações mudaram a calmaria política que pairava no Brasil há anos. Partindo de uma demanda aparentemente pontual em São Paulo - a revogação do aumento de 20 centavos na tarifa do transporte público - o Movimento "Passe Livre" (MPL) ganhou força nacional e levou milhares de pessoas às ruas das principais capitais brasileiras. A intenção deste artigo é discutir os motivos das manifestações, partindo das reinvidicações nas políticas públicas de transporte.

É curioso, mas talvez a participação política hoje seja muito mais dinâmica do que antigamente - quando se passava o dia inteiro discutindo a palavra de ordem e a resolução dos conflitos - substituindo profundidade por velocidade. De toda forma, a superficialidade individual permanece, já que a complexidade só tem sentido em ações coletivas. O grande risco é de o movimento se tornar absolutamente inócuo e não conseguir alterar o status quo. Isso foi o que ocorreu, por exemplo, no Occupy Wall Street, em 2011: movimento contra a desigualdade econômica e social que levou milhares de pessoas ao distrito financeiro de Nova York e depois se espalhou por outras cidades dos Estados Unidos e do mundo. Apesar de sua intensidade e do espaço que alcançou na mídia, o movimento não causou (até agora) transformações efetivas.

As manifestações por todo o Brasil representam uma oportunidade única de se mudar o status quo vigente. No entanto, se não houver cuidado, podemos perder essa chance e toda a mobilização terá sido em vão. A principal questão é: de quem é a rua? Hoje em dia, ela é dos carros. Se quisermos mudar o ambiente urbano, os pedestres, os ciclistas e o transporte público precisam ter maior participação nesse espaço. 


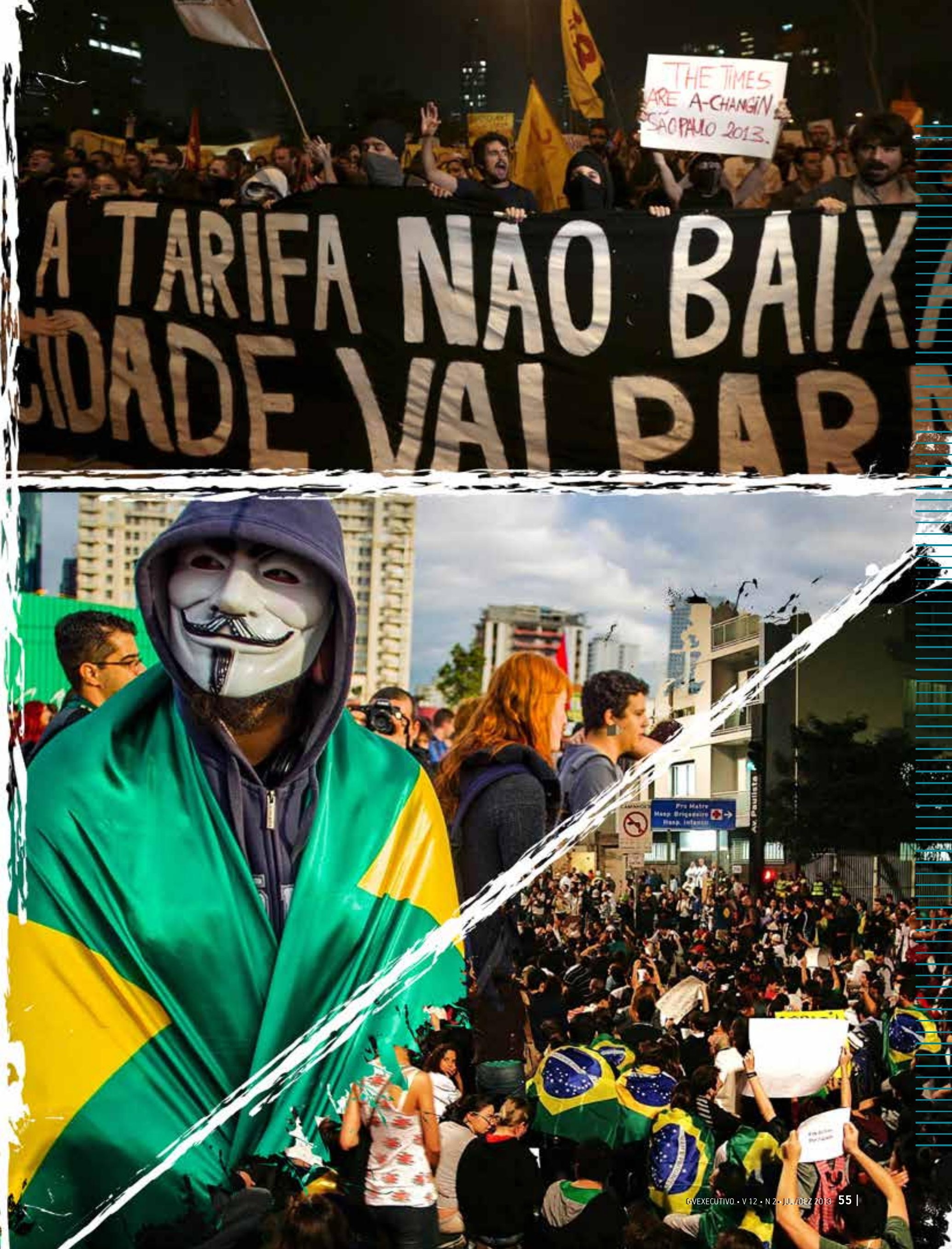




\section{CONFLITOS NO TRANSPORTE}

Depois de anos alienados dos problemas do País, os jovens foram para as ruas questionar a política de transporte público, que ganhou, então, o seu merecido espaço.

Apesar da admiração que esse grupo merece, a proposta de redução da tarifa está apenas na superfície do problema. Para enfrentá-lo com maior chance de sucesso, é necessário encarar a discussão sobre os conflitos que estariam por trás dessa proposta. O primeiro conflito é orçamentário, pois, com um orçamento equilibrado, é necessário aumentar impostos ou reduzir investimentos. O segundo encontra-se nos diferentes tipos de transporte, pois, ao favorecer o público retira-se espaço do particular, afetando a articulação entre os modais (sobre trilhos, rodas etc). $\mathrm{O}$ terceiro relaciona-se com a atual gestão do sistema, seja para aumentar sua eficiência, seja para reduzir a corrupção.

\section{QUEM GANHA COM A REDUÇÃO DA TARIFA?}

Apesar de muitos pensarem que a redução da tarifa beneficia mais os pobres do que os ricos, isso não é necessariamente verdade. No mercado de trabalho formal, o vale-transporte desconta no máximo $6 \%$ do salário do trabalhador. Esse valor não depende do preço da passagem, mas sim de sua remuneração. Uma pessoa que recebe R \$ 2 mil pagaria R 120 (6\% de R\$ 2 mil). Caso a tarifa aumentasse para $R \$ 3,20$, esse trabalhador continuaria gastando $\mathrm{R} \$ 120$, pois é o teto referente ao seu vale transporte. Assim, o retorno da tarifa para $\mathrm{R} \$ 3,00$ beneficia apenas os que ganham acima de R $\$ 2$ mil por mês.

É possível que a diminuição da tarifa tenha um efeito progressivo no mercado informal, beneficiando os que têm remuneração mais baixa e não recebem o vale-transporte. No entanto, há controvérsias nesse ponto pelo fato de muitos trabalhadores que não são registrados terem rendimento médio superior ao assalariado formal.

Outros beneficiários seriam turistas e usuários eventuais. Se considerarmos que o desempregado têm direito a transporte gratuito por um determinado período e que os estudantes usam o sistema intensivamente (do ensino médio em diante), é difícil acreditar que o impacto da tarifa seja efetivamente progressivo (ou seja, beneficie mais os pobres do que os ricos).

A única maneira de transformar essa política seria cobrar a conta dos usuários de carro. Se aumentarmos a carga tributária sobre esse grupo, teríamos como compensar o fato de que a redução da tarifa do transporte público beneficia mais os usuários que possuem maior poder aquisitivo.

\section{AS MANIFESTAÇÕES SÃO UMA OPORTUNIDADE ÚNICA DE MUDAR O CENÁRIO. MAS É PRECISO CUIDADO PARA NÃO PERDERMOS ESSE ESPAÇO E TODA A MOBILIZAÇÃO TER SIDO EM VÃO}

\section{UMA NOVA ALTERNATIVA PARA O CONFLITO MODAL}

Uma maneira de chegar a uma tarifa mais baixa em longo prazo é diminuir o espaço ocupado pelos carros. Imagine que a velocidade dos veículos do transporte público dobre. Nesse caso, o mesmo ônibus será capaz de realizar o trajeto na metade do tempo, sendo necessária apenas metade do número de veículos e metade da quantidade de motoristas e cobradores para oferecer o mesmo serviço que se tem hoje. Como o custo de operação dos veículos (incluindo mão-de-obra) representa cerca de $80 \%$ do custo total do sistema, dobrar a velocidade dos ônibus significa uma redução de $40 \%$ nesse custo do transporte público sobre rodas.

Uma alternativa para aproveitar o espaço retirado dos carros - que está nos planos da prefeitura e representa uma mudança estrutural nos transportes - é a implantação do chamado Bus Rapid Transit (BRT), uma rede de corredores totalmente isolada, com espaço para ultrapassagem e entrada pré-embarcada. Essa é a única maneira de dobrar a velocidade de um sistema de ônibus no horário de pico. Uma rede de $500 \mathrm{~km}$ de BRT pode atender metade das viagens realizadas em ônibus tradicionais. A criação de uma rede de metrô seria de oito a dez vezes mais cara. Não é à toa que o valor da passagem em Londres custe cerca de R \$ 10, em Paris mais de R 55 e em Tóquio, chegue a $\mathrm{R} \$ 15$. Em todas essas cidades, o subsídio percentual é consideravelmente maior do que em São Paulo, pois o sistema estrutural de transporte é o metrô-ferroviário.

É curioso que o conflito modal (entre tipos diferentes de transporte) tenha sido ignorado pelas manifestações. Essa é certamente a chave para uma mudança efetiva do transporte público. Um sistema sem velocidade tem alto custo e não é capaz de atender às necessidades das milhares de pessoas que dependem do transporte de massa em uma cidade como São Paulo.

\section{TEMPO DE DESLOCAMENTO OU REDUÇÃO NA TARIFA?}

Em minha visão, a qualidade do serviço é muito mais relevante do que o seu preço. Em 2010, o custo da 


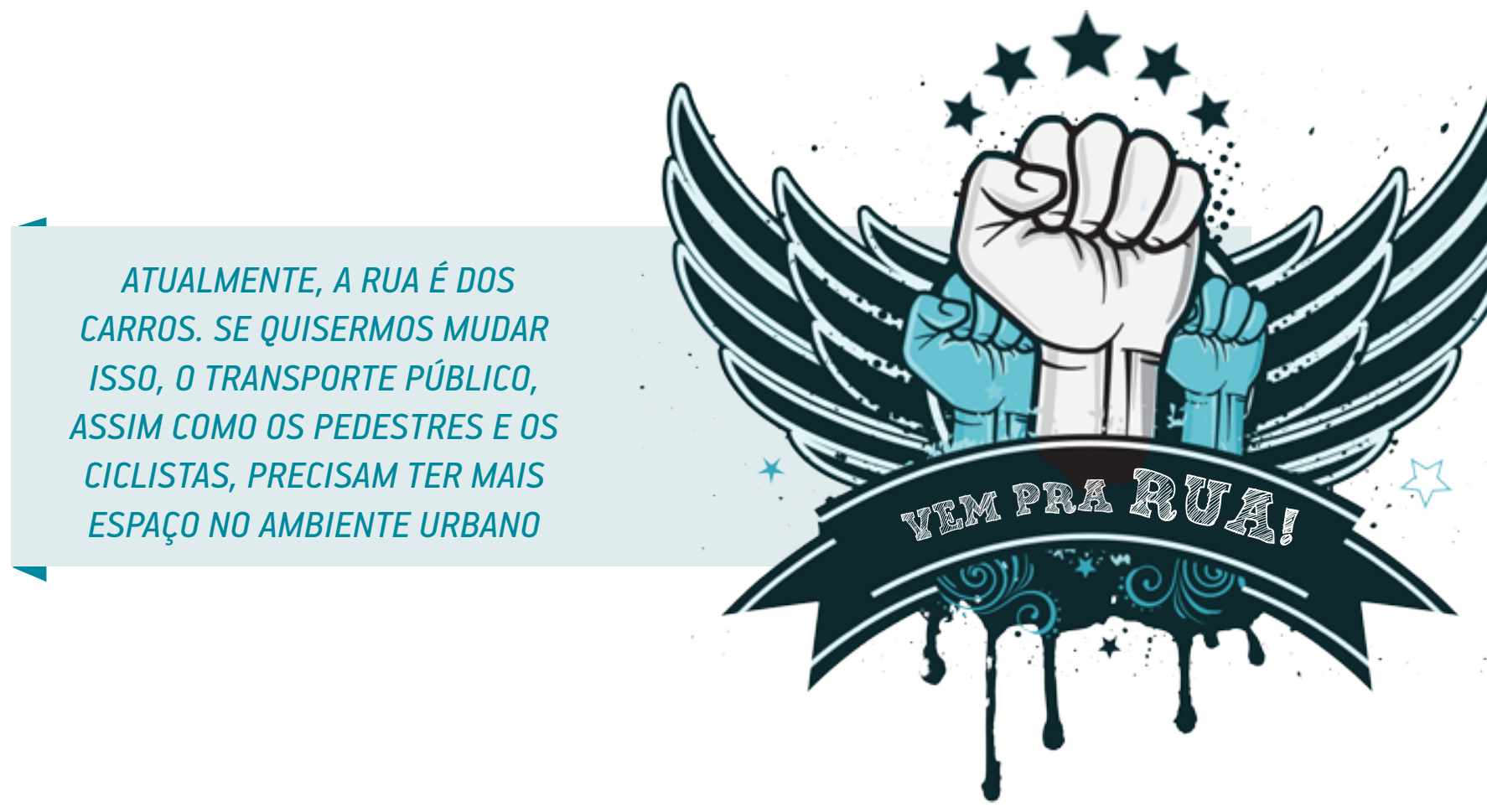

passagem para o usuário em São Paulo equivalia, em média, a 14 minutos de trabalho por dia - número bem acima da maioria dos países desenvolvidos. Portanto, uma redução de 14 minutos no tempo de deslocamento traria o mesmo benefício da tarifa zero. Significa que a diminuição de 20 centavos na passagem representaria uma economia de tempo equivalente a menos de 1 minuto. Em outras palavras, nesse contexto, a redução no tempo de deslocamento representa um benefício monetário maior do que o valor da tarifa.

Com uma rede de transporte de alta qualidade, podemos pensar no aumento do subsídio. Claro que os ganhos de produtividade podem ser incorporados na tarifa durante o investimento, mas a proposta apresentada aqui prioriza o investimento em qualidade, em face do aumento no preço da passagem. O governo é muito mais relevante como investidor do que no custeio do transporte, principalmente pelo fato dos mecanismos de proteção às fraudes dificultarem a gestão do sistema. Mas há outras opiniões.

\section{O MONSTRO EM MOVIMENTO}

Parece-me que a figura para descrever as manifestações é a de uma rede. A palavra de ordem - tarifa zero - funcionou como um vírus, que conquistou os participantes e colocou o "monstro em movimento". O MPL mostrou-se capaz de influenciar diretamente nas decisões de políticas públicas e serve como exemplo na luta por melhorias, pois foi feita de forma consciente, com os participantes requisitando seus direitos por uma causa justa.

Esse poder de mobilização que permitiu a influência direta da população na política de transporte geraria uma capacidade de monitoramento nunca alcançada pelas autoridades. Em um mercado sem concorrência, faltam incentivos para a busca da eficiência, pois o objetivo dos atores do mercado (incluindo o setor público) é fornecer o serviço. Para eles, conviver com uma tarifa defasada exige que a eficiência e a qualidade sejam prioridades, sobretudo se houver cobrança da sociedade.

Se pensarmos que esse foi o início de uma batalha e não o fim da guerra, o movimento pode incentivar uma transformação efetiva no status quo; esse é o seu objetivo mais profundo. As pessoas geralmente têm medo do novo e, em geral, adotam uma posição conservadora, sobretudo quando se fala em políticas públicas urbanas. $\mathrm{O}$ movimento abriu a possibilidade de melhorias e desenvolvimento, mas o filme está apenas começando e, até agora, ninguém sabe quem são os vilões e nem para quem torcer. A sociedade não pode mais se omitir; a hora é essa e não depende somente do governo. Transporte público de qualidade a preços módicos já! Vamos juntos nessa...

CIRO BIDERMAN > Chefe de gabinete da SPTrans e Professor da FGV-EAESP > ciro.biderman@fgv.br 